another $23 \%$ reported they spend 17 to 20 minutes per patient, and $22 \%$ said they spend 9 to 12 minutes with each patient. Primary care physicians overall devote considerable time to paperwork and administration, with $33 \%$ of self-employed and $27 \%$ of employed primary care physicians reporting that it takes 10 to 14 hours per week.

Regarding career satisfaction, family physicians ranked highest in terms of saying they would choose a career in medicine again, with $73 \%$ reporting that they would. But only $32 \%$ of family physicians said they would choose the same specialty.

AAFP President-elect Wanda Filer, MD, MBA, of York, Pennsylvania, said that although she was "thrilled" to see that family physicians were the specialists most likely to say they would choose medicine again, she was concerned that so few of them would again choose family medicine as their specialty. She chalked it up to the stress of navigating an increasingly complex practice environment.

"I know that burnout is a huge issue, brought on, at least in part, by ridiculous administrative burdens that take us away from rewarding face-to-face time with patients- the real reason we went into medicine," Filer said.

Filer is encouraged to see residents and students "who are ready to change the world," but cautioned that more needs to be done to ensure that family physicians who have been in practice for a while retain that same enthusiasm.

"It is important to help all of our members rediscover and sustain the joy of practice," she said. "We work daily to mitigate those many burnout factors coming from the practice front."

According to the survey report, family physicians ranked eighth overall in terms of offering new ancillary services_-such as MRI, physical therapy, orthotics, or in-office surgery-in their practice in the past 3 years, with $23 \%$ saying they have offered a new service during that period.

The report also noted that overall physician participation in accountable care organizations (ACOs) continues to grow at a rapid rate, with the percentage increasing from just 3\% in 2011 to $30 \%$ in the 2015 survey report. Among primary care physicians, 35\% said they participated in an ACO.

Wergin remains optimistic that policy changes at the federal level and a shift toward a greater emphasis on primary care worldwide are promising trends.

"Our value is going to increase as it is already recognized in every other developed country in the world," he said. "Countries such as Canada and England realized you cannot build a health care delivery system without a strong primary care base, and they reimburse their primary care physicians in line with that value.

"We're behind those systems now, but we're moving in their direction."

\author{
Michael Laff \\ AAFP News Department
}

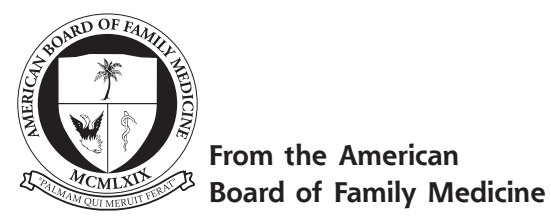

Ann Fam Med 2015;13:391-392. doi: 10.1370/afm.1828.

\section{THE AMERICAN BOARD OF FAMILY MEDICINE FOUNDATION INAUGURATES THE G. GAYLE STEPHENS KEYSTONE CONFERENCE SERIES}

Dr Gayle Stephens (August 6, 1928-February 20, 2014), one of the founders of family medicine in the United States, provided consistent intellectual leadership that profoundly impacted the specialty. He connected history, philosophy, religion, psychiatry, the family, the community, and the sciences to the practice of medicine, and he explained how family medicine was a counter-culture within medicine, manifested in personal relationships and rooted in social change. He particularly advanced the importance of relationships in clinical practice and the role of the personal physician as a trusted and trustworthy agent for patients. His obituary proclaimed:

Through his practice, teaching, writing, editing, and advocacy, Dr Stephens acted on his belief that, "Medicine is a moral vocation that is practiced best when patients have a personal physician who can help them get what they need from the larger system in a manner that does not demean or exploit them, a personal physician who is able and willing to attend to their patients' life experiences and individual preferences."

Dr Stephens was a prolific writer and his extensive body of written work was highlighted in a 2011 Family Medicine article, "G Gayle Stephens Festschrift," written by John Geyman, MD, another founding leader in family medicine and contemporary of Dr Stephens. Dr Geyman wrote that Dr Stephens:

"has been...by far the most original, thoughtful, and eloquent voice in our field and among the few who best represents the moral conscience of the entire medical profession. His wide-ranging intellect connects us with history, gives 
context for where we are now, and envisions alternative futures for our specialty, our profession, and society. Truly a renaissance man among us."

Obviously, his contributions were recognized by many, and confirmed by his election to the US National Academy of Science's Institute of Medicine, now known as the National Academy of Medicine. For many, Dr Stephens was the "poet laureate" of family medicine.

In addition to his institutional leadership, textbooks, scientific articles, essays, visiting professorships, and invited lectures, Gayle initiated an unusual invitational conference, known as "The Keystone Conference," where a relatively small group of colleagues could discuss ideas and discern important challenges and opportunities meriting the attention of family physicians and medicine as a profession. The third Keystone Conference inspired the Future of Family Medicine project that guided family medicine through the first years of the 21st century. In an effort to support the continuation of Dr Stephens' lifelong work and service, the American Board of Family Medicine Foundation established "The G. Gayle Stephens Keystone Conference Series" in 2014. The aim of this series is to continue his legacy of occasional, carefully constructed, invitational conferences focusing on relevant, challenging, perhaps neglected topics worthy of substantial consideration by family physicians, other health care professionals, and the public.

The inaugural conference in this series, the fourth Keystone Conference, was held June 5 to 7, 2015 near the Stephenses' family home at the Keystone Resort in Colorado. It followed the basic purpose and strategies employed by Dr Stephens in the first 3 Keystone Conferences and focused on the question, "What promises will a personal physician make to her/his patients going forward in the evolving health care system of the United States, particularly in terms of when and where they will be there for their patients?" It was conceived and planned by a multigenerational planning committee comprised of family physicians, including the remaining members of the "Keystone Quartet" that included Dr Stephens and which organized the third Keystone meeting.

This conference featured conversations stimulated by four plenary speakers. Dr Rosemary Stevens placed the conference into the ongoing history of medicine in the United States; Dr Will Miller illuminated the role of relationships in personal doctoring; Dr Kim Griswold examined the importance of place in personal doctoring, and Dr David Loxterkamp reflected on how time impacts personal doctoring. Most of the conference was streamed live and recorded. It is archived at http://www.gaylestephensconference.com where it can be viewed by those interested in how their own answer to the conference question compares or contrasts with what emerged. The recordings of the conference will remain available indefinitely.

From time to time, future G. Gayle Stephens Keystone Conferences will be held to investigate the issues that Gayle held so closely and which were so formative for the specialty. These issues remain foundational to the delivery of healthcare in this country as so aptly summarized by Howard Stein, PhD in the announcement of Gayle's passing by the Society of Teachers of Family Medicine:

"Gayle's prescient and prophetic voice is needed as much now as it was beginning in the late 1960s—not only for family medicine, but also for all medicine. The torch is now ours,"

The American Board of Family Medicine is honored to carry on the tradition of the Keystone Conferences and deeply grateful to the Stephens family for their permission to use their name to assure such reflective efforts continue in perpetuity.

$$
\text { Larry A. Green, MD and James C. Puffer, MD }
$$
American Board of Family Medicine 